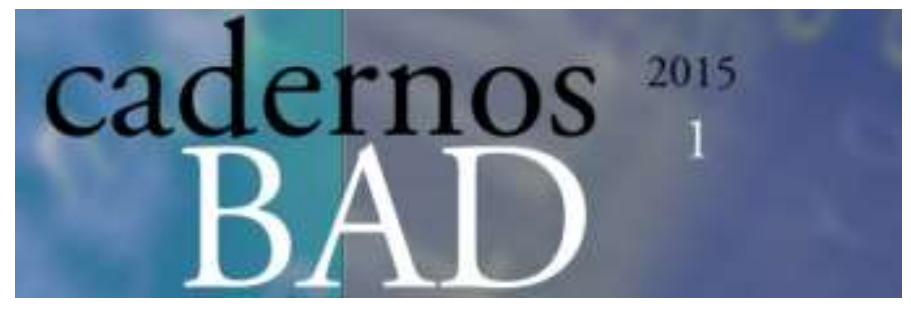

\title{
The Future of Scholarly Communication
}

\section{Deborah Shorley ; Michael Jubb}

O CILIP (Chartered Institute of Library and Information Professionals), cuja casa editora associada é a Facet, tem vindo a editar publicações para bibliotecas e profissionais de informação com uma grande abrangência. Esta associação apoia 0 desenvolvimento de competências e habilidades técnicas nos bibliotecários e profissionais de informação, promovendo a excelência através do conhecimento e reflexão sobre as práticas. A obra The future of scholarly communication surge nesta senda. Trata-se de uma obra em que os autores Deborah Shorley e Michael Jubb reuniram um conjunto de especialistas de diversas proveniências para proporem pistas de reflexão sobre o futuro da comunicação académica.

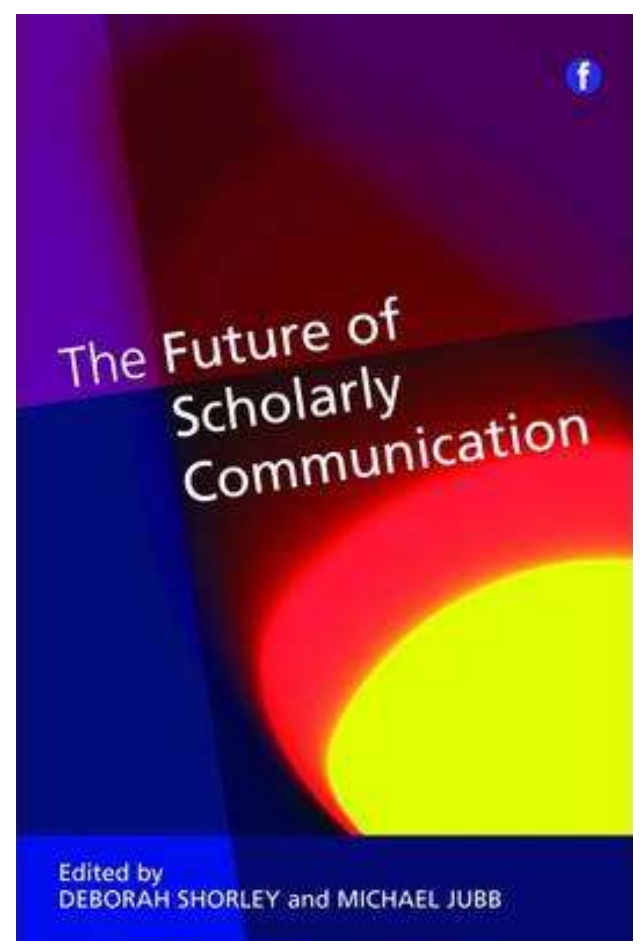

Porque poderá interessar este tema aos bibliotecários portugueses? A comunicação académica é uma importante etapa da produção científica. Trata-se de um dos grandes objetivos do processo de pesquisa, avaliação, análise, processamento e síntese de informação. A literatura especializada converge para algumas ideias que atravessam a produção e escrita académica e que assentam no pressuposto expresso na primeira página da obra Publication Manual of the American Psychological Association (APA, 2010, p. 9) e que refere «Research is complete only when the results are shared with the scientific comunity». Esta obra trata exatamente dessa partilha de conhecimento científico com a comunidade académica e com a sociedade civil, porém não faz com que a investigação termine aqui. Como referido por um dos colaboradores da obra, a comunicação académica é uma parte vital do processo de investigação em si, inspirando investigadores ao longo de 
novos caminhos de descoberta e permitindo a criação de conexões entre os conceitos e as pessoas (Shorley \& Jubb, 2014, p. 39).

As bibliotecas, em particular as universitárias, devem estar cientes deste ciclo de produção científica que pode ser explicado muito sucintamente a partir de três etapas principais. A primeira inicia-se com uma pergunta de investigação, que incita o estudante ou o investigador a procurar a informação em fontes primárias, bases de dados, bibliotecas, fomentando a produção intelectual. A segunda centra-se no processo de publicação e envolve a submissão de propostas de artigos científicos, capítulos, livros e a sua revisão, edição e desejavelmente publicação pelos editores. A terceira é a fase recepção do conhecimento pelos utilizadores e pela sociedade em geral, através do acesso a bibliotecas, bases de dados, repositórios, motores de busca, cópias impressas, entre outros. É a fase em que o conhecimento passa para a esfera pública.

Tendo este contexto em consideração, a importância desta obra parece-nos evidente. Michael Jubb começa por fazer uma introdução em que reflete sobre o que chama de disrupções numa ecologia complexa. Aponta pistas de leitura para os capítulos seguintes, sublinhando a importância da comunicação entre os investigadores (das diversas comunidades internacionais) e entre estes e as comunidades científicas, as pessoas e as organizações interessadas nas suas descobertas. Jubb destaca que as mudanças sentidas nos processos de comunicação da ciência na segunda década do século XX são uma alteração drástica relativamente à evolução gradual sentida nos últimos 200 anos. Nessa sequência, analisa as principais dimensões da comunicação em ciência (globalização, interdisciplinaridade, aumento exponencial de informação e de dados disponíveis, multiplicação de suportes e canais de comunicação), para se referir aos novos papéis dos intervenientes e aos serviços emergentes que medeiam entre os autores e os leitores (editores, distribuidores, serviços de citação e métricas, questões de acesso aberto e repositórios, entre outros).

A obra desenvolve-se em duas secções que analisam respetivamente a mudança de comportamento de pesquisa por parte dos utilizadores e os papéis e responsabilidades de atores-chave envolvidos neste processo, incluindo investigadores, patrocinadores, universidades, institutos de investigação, editoras, bibliotecas e utilizadores em geral. Apesar de alguns dos capítulos se centrarem em exemplos concretos, estes são suficientemente abrangentes para que o leitor possa ter uma compreensão global do tema e observar que as propostas teóricas que emergem são facilmente transferíveis para outras realidades. Os principais tópicos incluem: Alterar a forma de partilhar pesquisas em química; $O$ apoio à pesquisa qualitativa em ciências sociais e humanas; Interdependências entre investigadores e comunicação académica; A comunicação criativa na cultura "publicar ou perecer"; Cibertaxonomia; Lidar com o dilúvio de dados; As redes sociais e a comunicação académica; A mudança do papel do editor no processo de comunicação académica; O ponto 
de vista do patrocinador; Mudando estratégias institucionais de investigação; O papel da biblioteca de investigação; A visão dos utilizadores da biblioteca.

A obra The Future of Scholarly Communication transporta-nos necessariamente para uma reflexão mais aprofundada sobre três temas interligados: o papel das bibliotecas e dos bibliotecários, num contexto informacional em mudança; o ensino superior e a investigação como fundadores de novas práticas de colaboração global; o lugar da comunicação académica na sociedade de informação, na cultura e no mundo atual.

A atualização profissional dos bibliotecários é um dos mais urgentes domínios de intervenção que nos deve mobilizar. As associações profissionais, os espaços públicos, as escolas técnicas e as universidades, as redes sociais, os encontros profissionais, são locais que propiciam o ampliar de perspetivas relativamente aos novos papéis dos bibliotecários e à sua forma de agir. Novos territórios se abrem para a atuação destes profissionais, expandindo as fronteiras da classe e desafiando a diferentes atuações. Vários autores já refletiram sobre a importância da adaptação da formação dos profissionais da informação para fazer face a estes novos desafios (por exemplo, Silva, 2010), ou sobre a importância de um perfil do profissional de informação que deverá ser mais abrangente, por exemplo, a partir de práticas pedagógicas em contexto profissional (Sanches, 2014). As preocupações com gestão de dados digitais e infraestruturas de redes globais, com a interação das tecnologias e com a resposta ao universo digital, exigem também uma particular atenção, designadamente naquilo que Furtado (2012) chamou de uma ética e uma cultura da informação para a inclusão social.

No ensino superior, diversas questões filosóficas sobre a construção do conhecimento, a necessidade e pertinência da formação superior do mundo atual, a manutenção ou exclusão de campos disciplinares do currículo, têm dado o mote para a investigação e debates atuais neste campo (Cromer, 1997; Barnett \& Griffin, 1997; Barnett, 2000). As formas emergentes de construção e transmissão do conhecimento vão certamente afetar o modo como as bibliotecas se posicionam face à informação, apelando a renovadas maneiras de construir e permitir o seu acesso. As redes e parcerias entre investigadores e entre instituições, as novas geografias da investigação que incitam e promovem a internacionalização, através da mobilidade estudantil, de docentes e de funcionários, incitadas por financiamentos, programas e projetos internacionais são também temas em aberto na discussão atual (Charle, Schriewer \& Wagner, 2006; Abramson, Bird \& Stennett, 1996).

Finalmente, os lugares da comunicação académica na sociedade de informação, na cultura e no mundo atual remetem-nos necessariamente para as questões sociais. As formas de comunicação académica são também representações das relações estabelecidas entre indivíduos, instituições, países. É importante por isso observar e compreender que movimentos sociais têm sido ativados e como as liberdades, violências, democracias ou 
conflitos têm sido potenciados pela revolução digital, mobilizando novas práticas políticas, económicas e sociais. Castells (2013, p. 30) reflete aprofundadamente sobre estes fenómenos, referindo a importância da comunicação socializada, já que o ser humano constrói significados ao interagir com o seu ambiente natural e social, transpondo movimentos emocionais para movimentos sociais. Apela assim a uma conexão das mentes, com a criação de significados para contestar poderes instalados, sublinhando que a contínua transformação da era digital amplia o alcance dos meios de comunicação para todas as áreas da vida social numa rede que é local e global, genérica e pessoal, numa configuração em constante mudança.

A comunidade académica é também questionada na medida que as suas estruturas, outrora fixas e assentes em lugares específicos de recolha, produção e disseminação da informação e do conhecimento, se encontram forçadas a uma maior flexibilidade a adaptação por via das alterações que esta complexa ecologia, para usar as palavras dos autores, trouxe aos comportamentos e dinâmicas entre investigadores. A este propósito cito as palavras de Bauman (2003, p. 129), quando reflete acerca da necessidade de uma comunidade:

«A insegurança afeta a todos nós, imersos que estamos num mundo fluido e imprevisível de desregulamentação, flexibilidade, competitividade e incerteza, mas cada um de nós sofre a ansiedade por conta própria como problema privado, como resultado de falhas pessoais e como desafio ao nosso savoir faire e à nossa agilidade.»

Infelizmente não poderá haver soluções individuais para questões sistémicas, pois, nas palavras deste autor, «é precisamente essa dependência de nosso saber e recursos individuais que produz no mundo a insegurança da qual queremos escapar»

Eis-nos enfim chegados à ideia central desta reflexão: a de que, através da pertença a uma comunidade académica, profissional, de conhecimento, se podem utilizar formas de comunicação renovadas para estimular conexões entre os membros dessa comunidade.

A comunicação académica, em particular, tem sido palco de profundas transformações. Meios e técnicas são substituídos tendo em vista uma adequação às exigências impostas por mais dados, mais informação, mais produção científica, mais resultados passíveis de serem usados em rankings, fatores de impacto e outras métricas. Em The Future of Scholarly Communication os autores foram sensíveis a esta rede de influências e mostram, sobre as diversas perspectivas compulsadas na obra, o impacto dessas mudanças em diferentes atores, incluindo editores, investigadores, bibliotecários e utilizadores. 


\section{Referências Bibliográficas}

APA (2010) - Publication Manual of the American Psychological Association. 6th ed. Washington: APA.

ABRAMSON, Mike; BIRD, John; STENNETT, Anne (1996) - Further and higher education partnerships: the future for collaboration. Buckingham: The Society for Research into Higher Education.

BARNETT, Ronald, ed. (2000) - Realizing the university in an age of supercomplexity. Buckingham: The Society for Research into Higher Education: Open University Press.

BARNETT, Ronald; Griffin, Anne, eds. (1997) - The end of knowledge in higher education. London: Cassel.

BAUMAN, Zigmunt (2003) - Comunidade: a busca por segurança no mundo atual. Rio de Janeiro: Jorge Zahar.

CASTELLS, Manuel (2013) - Redes de indignación y esperanza: Ios movimientos sociales en la era de internet. Madrid: Alianza.

CHARLE, Christophe; Schriewer, Jürgen; Wagnereds, Peter, compil. (2006) - Redes intelectuales trasnacionales: formas de conocimiento académico y búsqueda de identidades culturales. Barcelona: Pomares.

FURTADO, José Afonso (2012) - Uma cultura da informação para o universo digital. Lisboa: Fundação Francisco Manuel dos Santos.

SANCHES, Tatiana (2014) - "Desafios para os bibliotecários portugueses na esfera da educação superior: explorando territórios formativos". Investigar em Educação: revista da Sociedade Portuguesa de Ciências de Educação, 2014, v.1, n.2, p. 109-122. [Consult. 03 Nov. 2014]. Disponível em: http://pages.ie.uminho.pt/inved/index.php/ie/article/ view $/ 32 / 31$

SILVA, Armando Malheiro da (2010) - "Literacia informacional e o processo formativo: desafios aos profissionais da informação". Congresso Nacional de Bibliotecários, Arquivistas e Documentalistas, 10, Guimarães: Associação Portuguesa de Bibliotecários Arquivistas e Documentalistas, 2010 [Consult. 03 Nov. 2014]. Disponível em: http://www.bad.pt/publicacoes/index.php/congressosbad/article/view/224/22

SHORLEY, Deborah; JUBB, Michael (2013) - The future of scholarly communication. London: Facet. ISBN 978-1-85604-817-0

Tatiana Sanches 